\title{
CARDIAC ARREST
}

\author{
R. W. Portal, M.B., M.R.C.P. \\ Senior Registrar, Department of Cardiology, \\ The Middlesex Hospital, W.1.
}

OVER the past 20 years the rapid development of cardiac surgery has provided a great stimulus to the study and treatment of cardiac arrest. The occurrence of arrhythmias with the thorax open afforded ample opportunity to observe the behaviour of the heart under various conditions, its response to drugs, to direct massage and to defibrillating shocks. The experience gained in the operating theatre, based on earlier experimental work such as that of Hyman (1932), Wiggers (1936, 1940) and Hooker, (Hooker 1929, Hooker, Kouwenhoven and Langworthy, 1933), was quickly put to good account when cardiac arrest occurred in less favourable circumstances. It is not very long ago since Beck (1941) reported the first defibrillation of the human heart at operation; survival following this arrhythmia was then unlikely, but is now commonplace. The same author was later to demonstrate the possibility of resuscitation from ventricular fibrillation following myocardial infarction (Beck, Weckesser and Barry, 1956), a report which opened the way to the rescue of "medical" cases of cardiac arrest by means of an immediate thoracotomy. The stimulation of the asystolic heart by electrical methods, outlined by Hyman (1932), and established in clinical practice by Zoll and colleagues (Zoll, 1952; Zoll, Linenthal, Norman and Belgard, 1954), has now led to the widespread use of artificial pacing in patients with atrioventricular conduction defects. Of special relevance to the present discussion was the demonstration that repeated shocks of brief duration (about 4 milliseconds) passed through the intact chest wall could produce a regular series of ventricular beats, capable of maintaining the circulation for long periods; and equally important was the achievement of ventricular defibrillation in man by a similar external application of electrodes passing an alternating current of greater voltage and duration (Zoll, Linenthal, Gibson, Paul and Norman, 1956; Kouwenhoven, Milnor, Knickerbocker and Chesnut, 1957). This last development rendered it unnecessary to open the chest in order to terminate ventricular fibrillation, provided only the circulation could be maintained whe preparations for defibrillation were made. TPe means of doing this were afforded by Kouweenhoven and colleagues' introduction of externat cardiac massage (Kouwenhoven, Jude and Knickerbocker, 1960), an advance which sit once extended the sphere of cardiac resuscitation to places remote from the operating theatre.

Four years of experience have left no doupht that external massage can be an effective subs tute for the spontaneous pumping action of the heart, though none who has any experience of it will deny its limitations or its compfcations. Despite occasional voices of protest it has become the accepted immediate emertgency measure in the treatment of cardiac arrest, and where facilities for external defibridlation and pacing are available there ow seldom be either need or justification for ofewing the chest. The work of Safar and colleagues (Safar, Brown and Holtey, 1962) has show that significant pulmonary ventilation cannest be produced by sternal compression and must be provided by other means. The urgency of establishing an airway and oxygenating the blood is seldom less than that of restarting the circulation. The provision of equipment to deal with this emergency, of personnel use it, and of organisation to ensure prompt action, is a matter for each hospital to solipe in its own way (Don Michael, Taylor and Warlthier, 1962; Bentall, 1962) and will not Be further discussed. Every such case, however, resolves itself into four stages: the restoration of the circulation by mechanical or electrical stimulation of the ventricles, or by external massage (rarely by direct massage); the oxygenation of the blood if spontaneous respiration has ceased; the diagnosis of rhythm by the electrocardiograph; and the re-establishment of effective ventricular action. For these objects an external pacemaker and defibrillator most today be considered necessary appliances, without which lives may be needlessly lost.

\section{Procedure}

External Massage

The term "cardiac arrest" implies a sudd 
failure of cardiac output resulting from ventricular asystole, ventricular fibrillation, or its common precursor, rapid ventricular tachycardia (ventricular flutter). The diagnosis seldom presents any problem. Sudden loss of consciousness with absent pulses in major vessels, absent heart sounds and failure to recover after lying flat (to exclude a simple faint) justify the commencement of cardiac resuscitation. Unless a resistant surface such as a table or trolley is at hand, the patient should be placed on his back on the floor. Despite its obvious inconveniences this is the best surface on which to perform external massage; the firmest bed will nearly always prove too springy, and experience has shown that a fracture board under the mattress does little to improve the situation. It is quite impossible for the operator to gauge the amount of sternal compression he is producing when the whole of the victim's body is bouncing up and down. The technique of external massage (Kouwenhoven and others, 1960) has been widely publicised; the balls of the hands are best placed one on top of the other in the midline at the lower end of the sternum. The amount of force used varies with the age and build of the patient and can only be learnt by experience. A sharp movement is required, and the operator must restrain his tendency to massage too fast; time for diastolic filling of the ventricles must be allowed, and a rate of 60 or 70 strokes per minute should not be exceeded. It must be remembered that the presence of significant valve disease (whether stenosis or incompetence) will greatly reduce the likelihood of producing an adequate output and in severe cases will render the procedure useless. The best criteria of a satisfactory output are an improvement in colour, muscle tone and level of consciousness, contraction of the pupils and the production of arterial pulses. The latter can be difficult to assess owing to the jerk imparted to the body by massage; and when palpating the groin a venous pulse may be mistaken for an arterial one. It has rightly been pointed out, moreover, that creation of a pulse wave is not necessarily evidence of flow (Weale and Rothwell-Jackson, 1962).

The complications of external massage are well known and have received due publicity (Baringer, Salzman, Jones and Friedlich, 1961; Morgan, 1961; Clark, 1962). Fractures of ribs or sternum are common, but since they seldom give rise to serious sequelæ they are regarded as a relatively small price to pay for survival. Damage to abdominal viscera is more serious, and tearing of liver, spleen and kidney is on record. The possibility of hæmorrhage from such injury should be borne in mind whenever there is unaccountable hypotension after restarting the heart. Though such trauma figures prominently in the reports, it is only fair to add that failure to resuscitate, or death following resuscitation, has rarely been attributed to it.

\section{Ventilation}

If the onset of the arrest is observed and massage initiated immediately, spontaneous respiration may continue, perhaps in the form of deep, sighing inspirations. As the circulation to the medulla is restored, normal or nearly normal respiration may return. In this case the resuscitator may be justified in concentrating entirely on massage and restoration of normal rhythm. More often breathing has ceased and some form of artificial respiration is imperative. This may be done by mouth to mouth insufflation, either direct or through an airway or by a mask and bag. As soor as possible an endotracheal tube should be passed, and if this is available at the start, together with someone capable of inserting it quickly, time should not be wasted on less effective methods of ventilation. Oxygen should be given in all cases.

\section{Rhythm}

Having restarted the circulation by external massage and ensured an airway and adequate tidal volume, the two immediate vital steps have been taken. Provided they have been accomplished within three to four minutes of the arrest the patient has a chance of survivaI. At this stage ECG leads should have been connected and the underlying cardiac rhythm displayed; appropriate action to restore normal rhythm is not possible until this has been done. A monitoring ECG oscilloscope visible to all helpers is of great value, in addition to a direct writer for permanent recording of events. The act of external massage always causes an artefact in the ECG tracing, and so must be temporarily stopped while the spontaneous rhythm is determined. The resulting tracing will dictate further action.

(1) Ventricular asystole: No QRS complexes are seen. The occurrence of $P$ waves is not of great concern at this juncture. Though their presence without QRS complexes indicates atrio-ventricular block, their absence is not necessarily a sign of profound myocardial 
depression, for the patient may well have atrial fibrillation. As a first step the mechanical stimulus of a sharp blow with the clenched fist over the precordium may result in a ventricular ectopic beat (Scherf and Bornemann, 1960). This method is frequently effective in the asystole of Stokes-Adams attacks where it has proved possible by a regular succession of such blows to maintain ventricular action for long periods (Don Michael and Stanford, 1963). If this method fails, an external cardiac pacemaker may be tried. Early descriptions of the use of this instrument are given by Zoll and colleagues $(1952,1954)$ and by Leatham, Cook and Davies (1956). Several models are now available commercially. The principle common to all is the passage of a current through the heart by two electrodes (about $3 \mathrm{~cm}$. in diameter) placed on the chest wall, most conveniently in the fourth intercostal space at the left sternal edge and over the ventricular mass in the mid-axillary line. The pulse is either of condenser discharge type or a monophasic square wave, duration 2-4 milliseconds, and the voltage required for an adult is usually in the region of 100 . The shock initiates a ventricular contraction in a way analagous to the mechanical stimulus described above, and an ECG recorded at the time shows the large stimulus artefact followed by a deformed QRS complex and $T$ wave. Impulses are delivered at a physiological rate of 60 to 80 per minute. The shock is painful and the patient may protest on regaining consciousness. Should this be so, an injection of morphine or pethidine will usually permit continued use of the instrument provided the voltage is kept to the threshold level of ventricular response. If necessary the heart can be kept beating regularly in this way for hours on end.

Experience has shown that the external pacemaker is of greatest value in the asystole of Stokes-Adams disease and in the less common cases due to quinidine or digitalis intoxication. Asystole following myocardial infarction or in the course of valvular heart disease is less likely to yield to this method, for here one is dealing with a damaged myocardium and not simply a faulty conducting mechanism. It cannot be over-emphasised that mechanical and electrical stimuli are justified only in cases where the ventricles are capable of an effective contraction. If, in the presence of asystole, a few blows on the precordium or a few shocks with an external pacemaker do not result in clinical signs of an increasing cardiac output, these measures should be quickly abandone्d and external massage resumed, no matter whint the ECG shows. QRS complexes or oT waves may be hard to recognise owing to the stimulus artefact, and in any case are $\overline{\overline{\mathrm{m}}}$ evidence of a forceful mechanical systole. In such a situation an adequate output is mo likely to be obtained by massage than by $\overline{\bar{c}} \bar{a}$ feeble stimulated ventricular beat; this mळy be procured later following the correction of myocardial anoxia or acidosis, or occasionally by means of adrenaline.

When spontaneous ventricular action is ndt sustained after these emergency measures, aRd adrenergic drugs have failed to evoke a reliabise natural pacemaker, control of rhythm can be obtained by means of endocardial electricat stimulation. This involves the passage of electrode catheter through a superficial vein (usually the external jugular or antecubital) and the impaction of its tip in the right ventricle. The catheter is connected to a pacemaker and the circuit completed by a neutral electrode placed on or under the skin; the voltage required is low, usually well under two. Detaits of this method as an emergency measure been given elsewhere (Portal, Davies, Leat and Siddons, 1962). If necessary, pacing $\bar{c}$ be maintained in this way, or by modificatio of it, for many months (Furman, Schwed ब्্ु, Robinson and Hurwitt, 1961; Landegren and Biorck, 1963; Siddons and Davies, 1963) and experience so far has shown that complications from the intracardiac catheter are surprisingty few. Again it must be emphasised that pacing by catheter is simply a means of triggering off a ventricular contraction and depends for suse cess on the ventricles being capable of a forceful beat.

(2) Ventricular fibrillation. When the charae teristic irregular undulating pattern of ventricular fibrillation is seen, or the rapid more or less regular deflections of ventricular fluttes, external defibrillation should be attempted the earliest moment. The principle is to thron the whole ventricular mass into a refractory state so that the fibrillatory pathways are interrupted and a regular physiological pace maker can resume control. The electrodes used are larger than those of the external pace maker (about $8 \mathrm{cms}$. in diameter) but a similarly positioned on the chest wall, as much of the heart as possible lying between theng. When using an alternating current (A.C.) de्ष fibrillator a voltage of between 200 and 800 \% employed, the discharge being commonfy 
between 0.1 and 0.2 seconds in duration (Zoll and others, 1956; Kouwenhoven and others, 1957). The object is to pass a current of about 5 amps across the chest, a proportion of which will pass through the heart itself. The resistance between the electrodes is determined by their size, their contact with the chest wall (electrode jelly should be freely used) and the build of the patient. Direct current (D.C.) countershock is now becoming an accepted treatment for the correction of atrial fibrillation and other intractable arrhythmias (Lown, Amarasingham and Neuman, 1962; Oram, Davies, Weinbren, Taggart and Kitchen. 1963) and may replace the A.C. defibrillator in ventricular defibrillation. An advantage of this will be the use of a single instrument to deal with all arrhythmias except asystole, which will still require the pacemaker. Further merits of the D.C. instrument are its short pulse duration of about 4 milliseconds, which renders it less dangerous to the user, and its potential independence of the mains supply. It remains to be seen, however, whether D.C. defibrillation will prove more effective than A.C. or cause less tissue damage. Experience with the A.C. defibrillator hitherto has been gratifying, and where there has been failure this is more likely to have been the result of serious myocardial damage than any shortcoming of the instrument. Whichever model is employed the chances of success will be slender unless the myocardium is well oxygenated, and before any attempt at defibrillation is made special attention must be paid to details of massage and ventilation. A series of shocks at one-second intervals may be fruitful where a single shock fails (Wiggers, 1940). The adjuvant action of drugs will be discussed in the next section.

It is convenient, though by no means essential, to combine the electric resuscitation equipment into a single unit. Fig. 1 illustrates this principle. The "resuscitation trolley" contains a direct-writing electrocardiograph, an oscilloscope, a defibrillator and a pacemaker.

\section{Drugs}

Recommendations about the value of drugs in cardiac arrest are not easy to make, for a single experience may colour one's views, and there is the further difficulty that in the emergency several measures are employed simultaneously or in quick succession, so that it is often impossible to know where the credit is due for any success. The governing rule, however, is that oxygen is the body's prime need, and that once this has been provided and

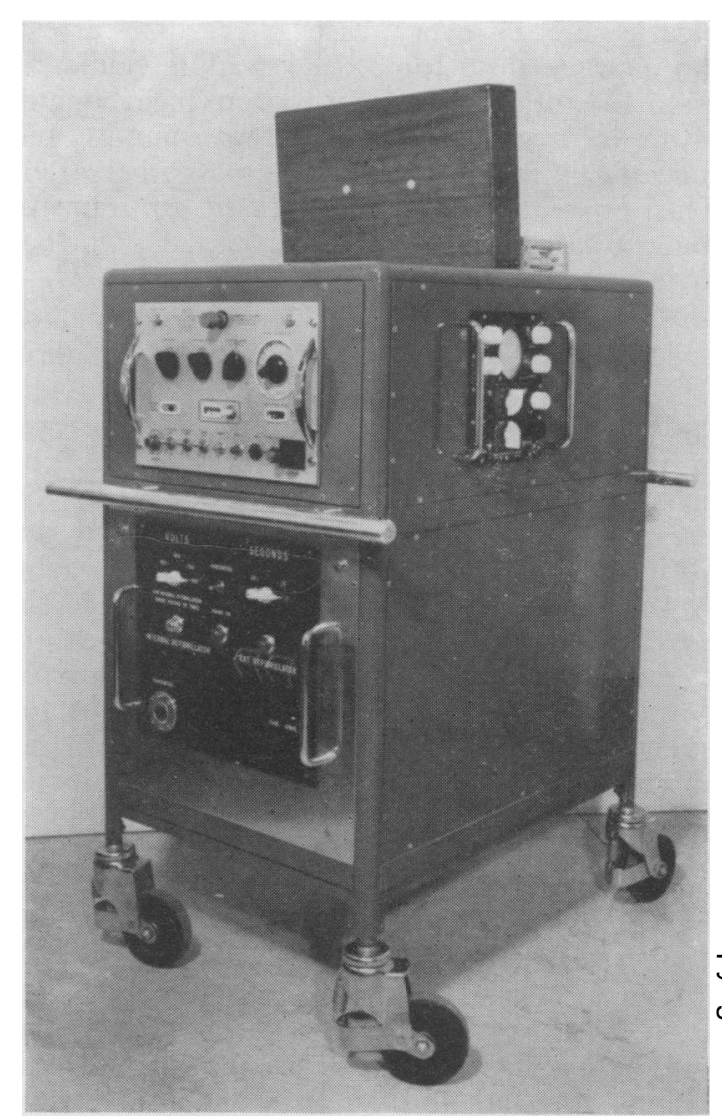

Fig. 1.-Resuscitation trolley, containing direct writing electrocardiograph, monitoring oscilloscope, defibrillator and pacemaker. The unit weighs $90 \mathrm{lbs}$ and measures $33 \times 24 \times 18$ inches (designed by Mr. R. G. Waterman, and built in the Engineer's Department of The Middlesex Hospital, W.1.).

the coronary and cerebral circulation restored, a sound myocardium requires nothing more. This would apply, for example, in the case of an anæsthetic accident, diagnosed promptly, in which normal rhythm was re-established after a few minutes of external massage. The second sound rule, based on experimental evidence (Ebert, Greenfield, Austen and Morrow, 1962; Ledingham and Norman, 1962) and established in clinical practice (Brooks and Feldman, 1962; Stewart, 1964) relates to the administration of bicarbonate. Circulatory arrest, with its inevitable anoxia, results in the formation of metabolites from anærobic glycolysis. The degree of the ensuing metabolic acidosis increases with the duration of the arrest and is predictable. Myocardial function is impaired by acidosis, and improves when it is corrected. It is therefore rational to give 
bicarbonate in every case of cardiac arrest. An average dose for a $70 \mathrm{~kg}$ adult would be 60 to $120 \mathrm{mEq}$. (5-10 G. of sodium bicarbonate) given intravenously over a few minutes and repeated if necessary at intervals thereafter. This procedure can be expected to improve myocardial function, discourage further arrhythmias, and can do no harm.

There is experimental evidence that procaine amide increases the ease of defibrillation (Herrod, Lee, Goggans, McKombs and Gerbode, 1952) and the same is likely to be true in man (Julian, 1961). The drug should be given intravenously in a dosage of 250 to 750 mg. and is most clearly indicated when defibrillation has failed. There is little doubt, however, that correction of acidosis should have first priority, and the depressant action of procaine amide on the myocardium must be borne in mind. There is little or no place for quinidine. Sympathomimetic drugs such as adrenaline and isoprenaline may be of value in restoring myocardial tone or accelerating a sluggish ventricular pacemaker, but experience suggests that the intracardiac injection of such drugs, usually performed as a last resort, seldom affects the outcome. The same holds for calcium salts. Digitalis is rarely a consideration in the early stages of the emergency, but will be required later for such obvious indications as atrial fibrillation or failure. Pressor agents may be of value in maintaining blood pressure after restoration of ventricular action, and may occasionally improve myocardial function in the early stages by raising diastolic pressure and increasing coronary flow (Churcher, 1962). If consciousness is not regained the reduction of presumptive cerebral oedema by intravenous urea $(40-80$ G.) or hypertonic sucrose should be considered, as should the institution of hypothermia to reduce metabolism. For ease of administration of drugs an intravenous drip of dextrose solution is invaluable, and should be set up at the earliest possible moment after the arrest .

\section{Thoracotomy}

It is rash to be dogmatic on the present place of thoracotomy in cardiac arrest, and a wholesale discouragement of the measure is not intended. Lives will doubtless still be saved from time to time in this way, especially in the operating theatre and where means of defibrillation are not available. It can only be said that since Kouwenhoven's introduction of external massage the procedure is seldom called for, and experience suggests that when external defibrillation has failed the chances of saving the patient by opening the chest and employing direct massage and defibrillation are slender. When no facilities for defibrillation are at hand, the attendant will rightly feel im potent, especially when drugs have proveg unavailing; it should be remembered, howeve that oxygenation of the myocardium by con tinued massage may occasionally reverse th $\widehat{\Phi}$ arrhythmia. In the case of ventricular asystole unresponsive to mechanical or electrical stimuli there is probably even less to be gained by thoracotomy, the only exception being whe $\overrightarrow{\mathrm{n}}$ external massage has for some reason failew to produce an adequate output.

\section{Clinical Illustrations \\ Case 1}

A man of 54, without previous angina, had की myocardial infarct (Fig. 2) and was admitted tor hospital. The following day he suffered cardiag arrest. External massage was commenced withio a minute, followed by assisted respiration by endoo tracheal tube. The ECG showed ventricular fibril? lation. During external massage spontaneous respir ation was resumed, muscle tone remained good an the pupils small. A left thoracotomy was performed in the ward, cardiac output maintained by directo massage, and internal (A.C.) defibrillation carried oup with the operating theatre defibrillator. His spin taneous rhythm was now complete heart block, fup after two minutes fibrillation recurred. Followmg the injection of $2 \mathrm{ml} .0 .1 \%$ adrenaline and $400 \mathrm{mg}$ ? of procaine amide an effective idioventricular rhythm was obtained after four further shocks with the defibrillator. The total period of massage was 28 minutes. The patient was now anæsthetised and taken to the theatre where pacemaker wires were inserted in the right ventricle and the wound closed? An infusion of nor-adrenaline was required for two days to maintain blood pressure. The heart block was replaced by permanent sinus rhythm 24 hours after the arrest. His recovery was complicated by urea retention with blood and albumen in the urine, surgical emphysema, a chest infection an a normochromic anæmia, but he was eventually discharged 60 days after admission in good condio tion and with mental faculties unimpaired. Fig. 3 shows his ECG two months after resuscitation 0 $\mathrm{He}$ remains well, free from cardiac failure and angina, three years after the event.

Many examples of resuscitation by thoracotomy have been recorded since Beck's earlyn report (1956). At the time of this man's arrest an external defibrillator was not available, ando to terminate the arrhythmia there was now alternative to opening the chest. His subse? quent course would doubtless have beere smoother had external defibrillation beenes possible. That myocardial damage was considerable was shown by his dependence on pressor agents following resuscitation. The importance of correcting acidosis was not? realised at this time. 

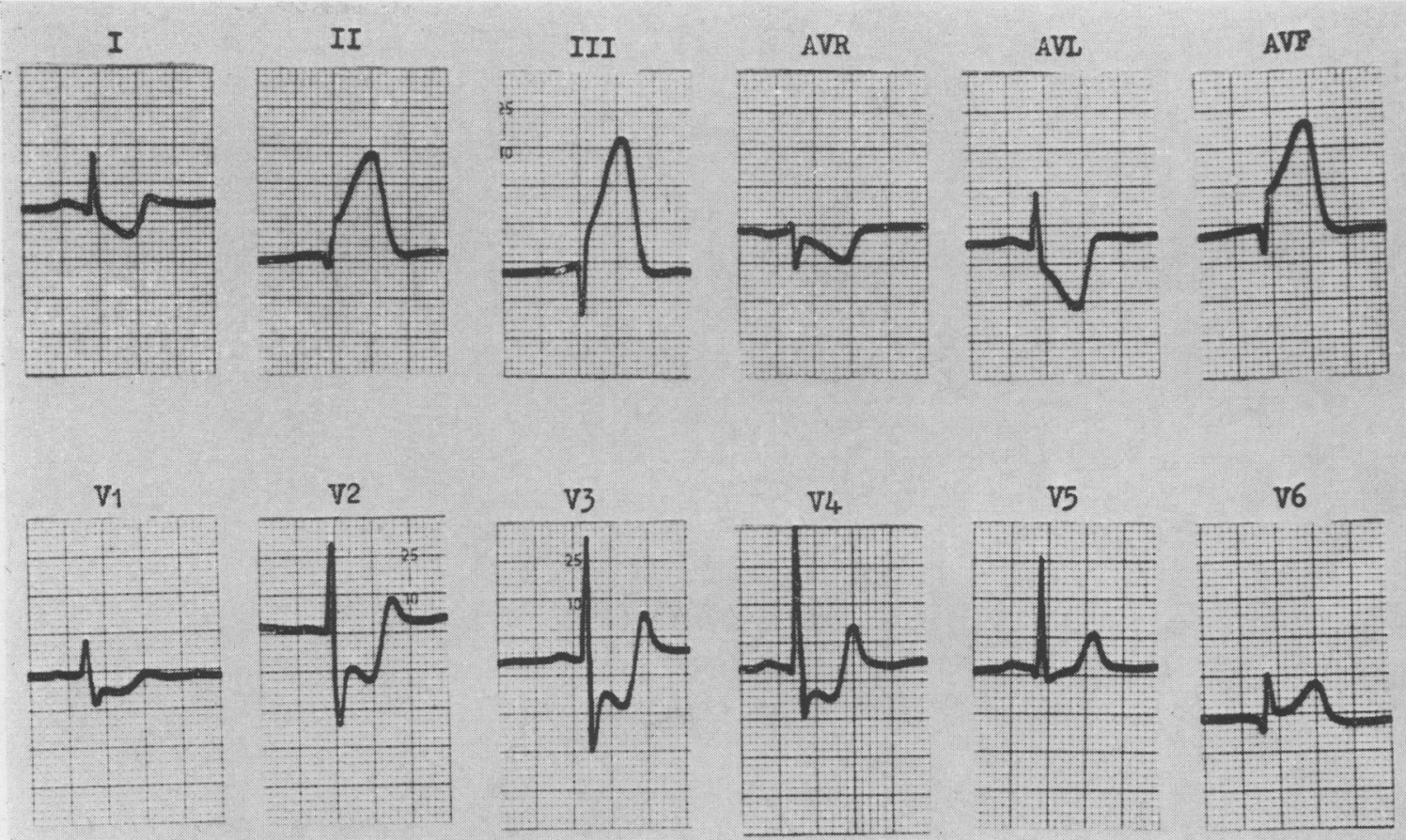

FIG. 2.-ECG of man aged 54 (case 1) showing recent posterior infarction and recorded 24 hours before cardiac arrest.

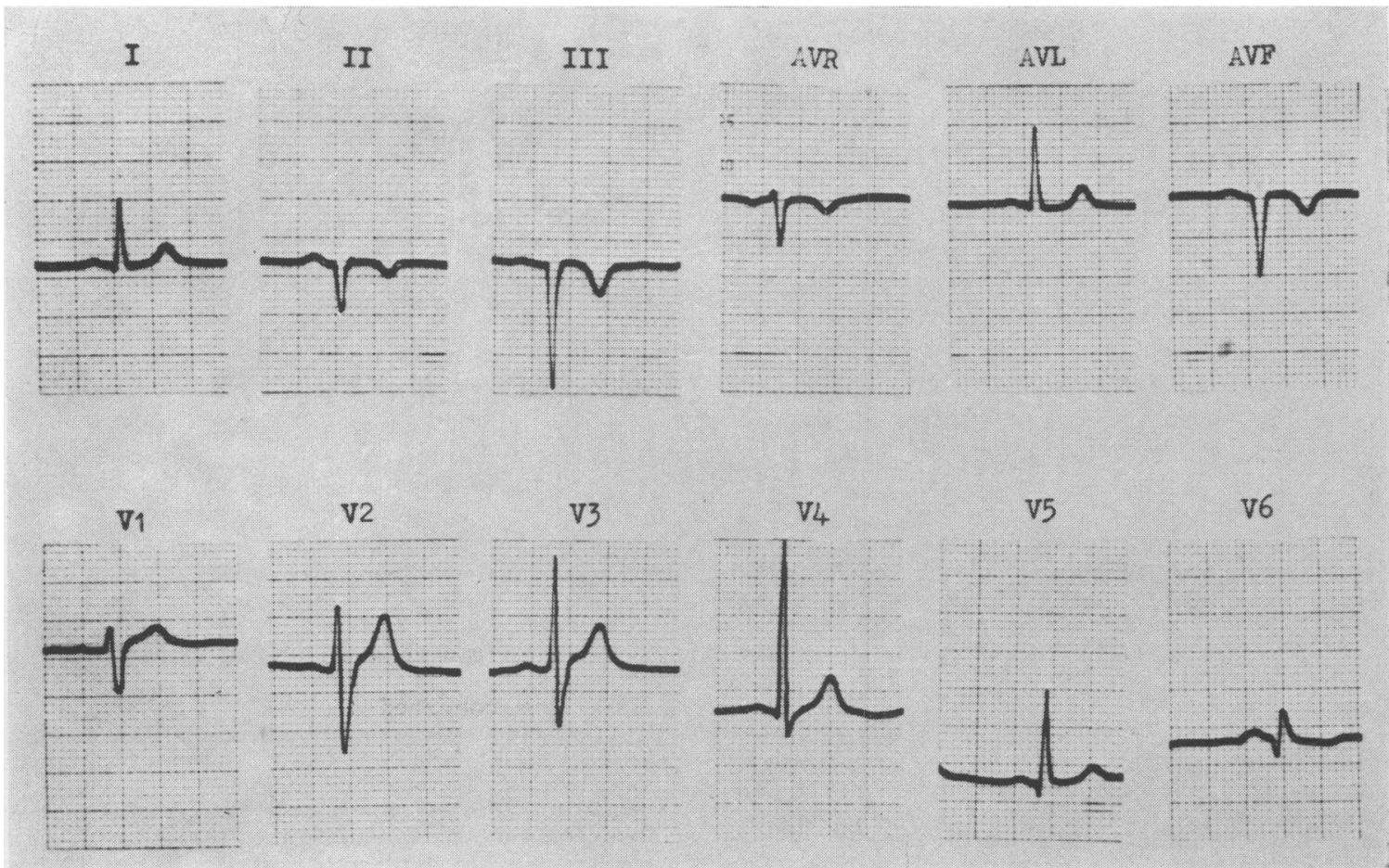

FIG. 3.-ECG of same patient as in..Fig. 2, recorded two months after resuscitation by thoracotomy. 
I

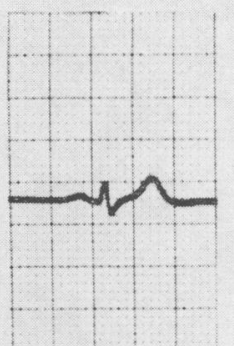

V1

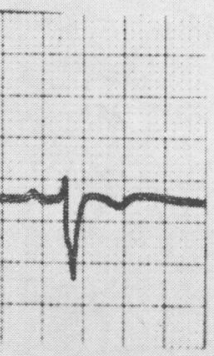

II

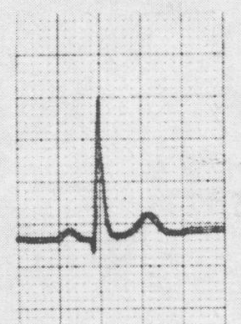

V2

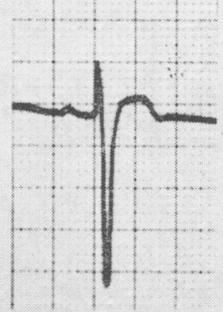

III

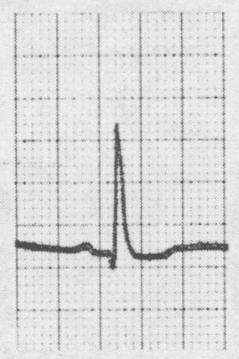

V3

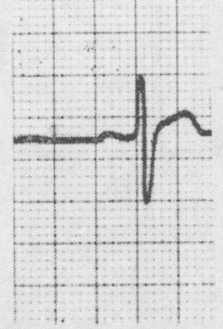

AVR

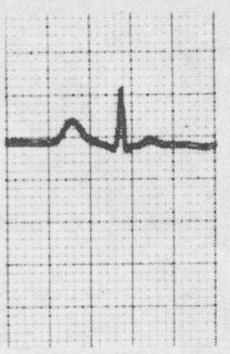

$\mathrm{V}_{4}$

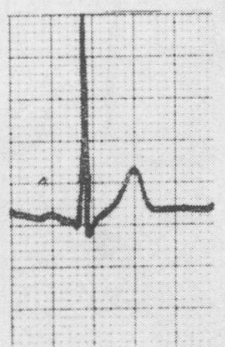

AVL

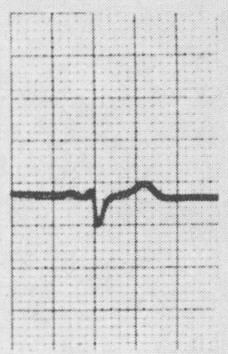

V5

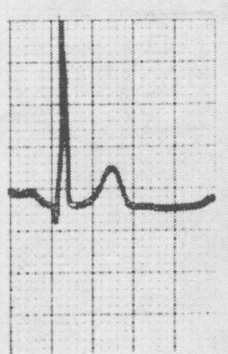

AVF

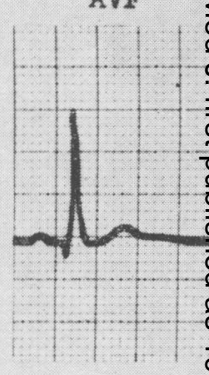

v6

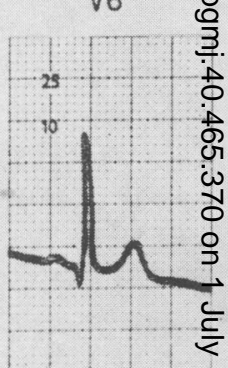

రి

FIG. 4.-ECG of 19-year-old youth (case 2) recorded two days after cardiac arrest. The circulation was maintained by external massage for 53 minutes before defibrillation was achieved.

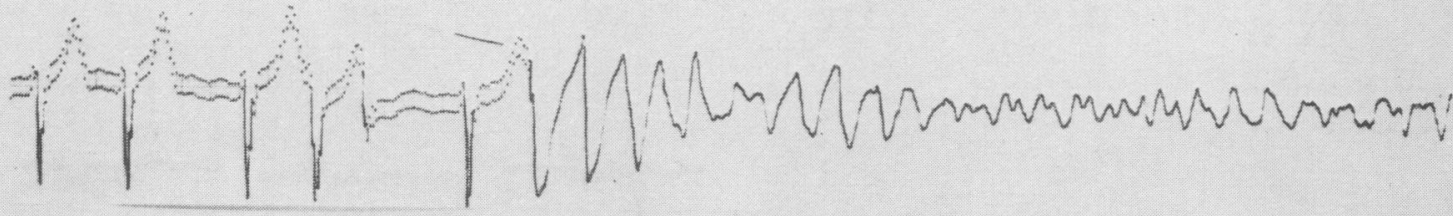

\section{Case 2}

A healthy, 20-year-old youth had a general anæsthetic for capping of his front teeth. About 50 minutes after the start of the operation cardiac arrest occurred. External massage was begun at once and ventilation continued by means of the endotracheal tube already in place. He was conveyed a quarter of a mile by ambulance to the hospital casualty department, massage and ventila- tion being continued the while. On arrival the ECG showed ventricular fibrillation. Two attempes to defibrillate failed; $6 \mathrm{G}$. of sodium bicarbonato and $300 \mathrm{mg}$. of procaine amide were given intra? venously, following which defibrillation was success ful. Immediately thereafter the ECG showed sinus rhythm and blood pressure was 120/80. A 12 leas ECG half an hour later was virtually normal. The total period of arrest and external massage was 59 


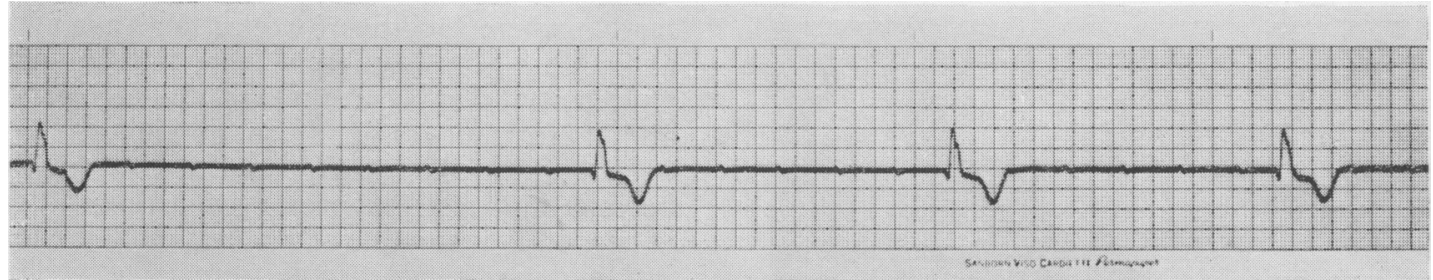

FIG. 6.-Complete heart block with ventricular asystole (case 6). The patient was suffering from repeated syncopal attacks. The interval between the first two QRS complexes is 5 seconds.

minutes. Consciousness was regained four hours later when he was talking rationally. There was guarding and rigidity of the abdomen for 36 hours, suggesting an intra-abdominal bleed, but surgical exploration was not required. There was no evidence of broken ribs or intra-thoracic trauma. He left hospital 17 days later, normal in all respects. Fig. 4 shows his ECG two days after the event.

The satisfactory outcome in this case was due to the prompt action of the anaesthetist in starting external massage and the fact that ventilation was readily maintained from the start by the endotracheal tube already in place. It demonstrates the results obtainable in this sort of emergency when circumstances are favourable and the correct procedure is carried out. It was probably not fortuitous that defibrillation was achieved only after the administration of bicarbonate and procaine amide.

\section{Case 3}

A 74-year-old man with heart block and StokesAdams attacks for three years had an internal cardiac pacemaker inserted in the left rectus sheath with the myocardial electrode implanted in the left ventricular wall. Artificial pacing was satisfactory till the 11th post-operative day when he suddenly lost consciousness in bed. He was lifted to the floor where external massage was begun. The ECG showed ventricular fibrilation with the pacemaker artefacts occurring normally at their original rate. External defibrillation was accomplished at the second shock about five minutes after the arrest, and the pacemaker resumed uninterrupted control of rhythm. Recovery of consciousness began during massage and the patient was aware of the defibrillating shock; spontaneous respiration never ceased and no artificial respiration was required. Since this episode pacing has continued uneventfully for 12 months, during which he has remained well and active.

The cause of this patient's fibrillation is unknown and the possibility of its being triggered by the pacemaker cannot be excluded, though this hypothesis is rendered less likely by his subsequent course. The period of arrest was short because the episode occurred in the daytime when assistance was immediately at hand. Recovery of consciousness during massage is frequently seen (Bernier, 1962; Cohen, Sumner, Whalen, Brown and McIntosh, 1962) and may call for light anaesthesia or an intravenous analgesic.

\section{Case 4}

A woman of 43 with rheumatic heart disease and atrial fibrillation had a left ventricular angiocardiogram. At the end of the injection ventricular fibrillation occurred (Fig. 5). External massage was immediately commenced. After 15 seconds the fibrillation terminated spontaneously with a return to the former rhythm. There was never complete loss of consciousness, respiration continued, and drugs were not necessary. On resumption of normal cardiac action she complained of severe burning headache due to the stagnation of medium (Triosil) in the cranial circulation during the period of arrest. This passed in a few minutes and there were no other sequelæ.

\section{Case 5}

A woman of 60 with congenital heart disease (the final diagnosis was Ebstein's anomaly) underwent cardiac catheterisation. As the catheter entered the pulmonary artery a run of ventricular ectopic beats occurred, followed immediately by ventricular fibrillation and loss of consciousness. Mouth to mouth respiration and external massage were started. An endotracheal tube was passed and the external defibrillator prepared. One shock (800 V., 0.1 sec.) resulted in defibrillation and restoration of former rhythm. She regained consciousness and in a few minutes was talking rationally. There were no sequelæ apart from a sore chest and a minor skin burn from the electrodes. The duration of arrest and massage was 15 minutes.

These two cases illustrate the occurrence of arrest during cardiac procedures and the importance of keeping a defibrillator at hand in the investigation room. In case 5 the instrument was 200 yards away at the time of the episode, thus explaining the delay of 15 minutes. In case 4 it will be seen from Fig. 5 that the duration of the true fibrillation pattern was short (about 5 seconds) and was quickly replaced by the more regular waves of ventricular tachycardia before the return of normal beats. Though the arrhythmia might have terminated spontaneously, this is highly unlikely and the rapid reversion can reasonably be attributed to the coronary flow produced by external massage. The termination of ventricular fibrillation without electrical defibrillation is not all that uncommon (Mody and Richings, 1962; Wetherill and Nixon, 1962; Harden, Mackenzie and Ledingham, 1963) but will rarely if ever occur unaided by cardiac massage or drugs. 


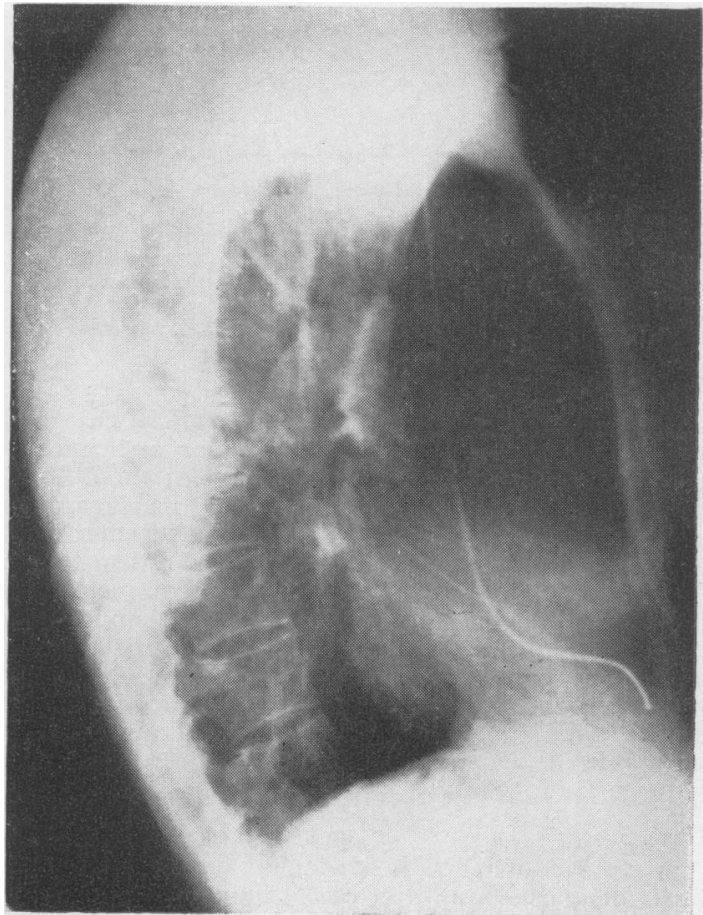

FIG. 7.-Lateral radiograph (case 6) showing electrode catheter on the apex of the right ventricle. This is the optimal site, from which dislodgement is unlikely.

\section{Case 6}

A fishmonger of 42 began to suffer from syncopal attacks due to intermittent heart block. A month after the onset of symptoms a severe bout of attacks occurred. These consisted of periods of ventricular asystole lasting up to 7 seconds (Fig. 6), sometimes with loss of consciousness, and improved only temporarily by subcutaneous adrenaline. During the periods of standstill ventricular ectopic beats could be provoked by a sharp blow on the precordium, and a series of such blows would terminate the attack. The external cardiac pacemaker was equally effective, but the patient found precordial percussion the less painful of the two. Since the attacks were occurring every few minutes a combination of these methods was used for an hour while preparations were made for endocardial pacing. Under fluoroscopic control an electrode catheter (Cournand 50 , No. 5) was passed via the right external jugular vein to the right ventricle. When the tip was suitably positioned (Fig. 7) pacing was started and the attacks ceased (Fig. 8). Control of rhythm by catheter was continued for 15 days until an internal pacemaker was inserted. This has functioned well for the past year during which the patient has been running his business and remained free from attacks. Apart from the conduction defect there is no evidence of cardiac disease. His brother had suffered from similar symptoms eight years earlier, and had died in a Stokes-Adams attack at the age of 38 . Artificial pacing was at that time in its early days..

The emergency control of recurrent StokeAdams attacks has become a relatively simple matter where facilities for electrical pacing a available. Many sufferers from this compla角t have a sound myocardium, as did this patient, and there is no difficulty in obtaining a googd output from the heart, provided it has not become anoxic from prolonged arrest; all that is needed is a suitable stimulus. Both mechæical and electrical stimuli were effective he $\overline{\overline{v e}}$. Once the catheter was in position control क्ष rhythm was assured, and drug therapy became unnecessary. This method of pacing causes no discomfort to the patient, and as well $₫$ preventing asystole will also protect him against syncope due to bursts of rapid ventricuear tachycardia. A pocket sized pacemaker g్gs readily attached to the catheter to make hin ambulant.

\section{Case 7}

A man of 64, with mitral incompetence, atrial fibcullation and a cardiothoracic ratio of 0.70 wals admitted to hospital in an attempt to control foquent ventricular ectopic beats. $\mathrm{He}$ was not in cardiac failure. When talking to his physician on a ward round he collapsed with cardiac arrest. He was placed on the floor where external massage was commenced. An endotracheal tube was passed and oxygen given. The ECG showed ventriculer fibrillation. Though external defibrillation owas achieved there were repeated relapses and the ation was not improved by bicarbonate, prosinio amide or intra-cardiac adrenaline. Massage was 60 tinued for 40 minutes during which he was sen conscious and making purposive movements. Despipe this evidence of cerebral blood flow effective vertricular action could not be procured and resusetative measures were abandoned. Autopsy showed $\overrightarrow{{ }^{a}}$ hypertrophied left ventricle with mitral incompetenge but no coronary artery disease.

\section{Case 8}

A man of 55, without preceding angina, had myocardial infarct. Five minutes after arrival the ward he collapsed with ventricular fibrillatiog. External massage was started and ten minutes later external defibrillation was easily achieved with recovery of consciousness and resumption of sinos rhythm. The ECG showed antero-septal infarction. His condition remained satisfactory for 18 hou when he again lost consciousness, the ECG this time showing intermittent A-V dissociation wi periods of asystole. An electrode catheter was passed to the right ventricle and pacing started. During f $_{\text {f }}$ test period off the pacemaker eight days later - a further syncopal attack occurred, and a longer rot of uninterrupted pacing was planned in the hope that the rhythm would stabilise. Two days later however, ventricular fibrillation again occurred, and though defibrillation was twice successful adequate myocardial function could not be restored. Autop showed occlusion of the descending branch of the left coronary with an anterior infarct involving nearly the whole of the septum.

The above two cases illustrate the difficul of resuscitation in the presence of seriofs cardiac damage. Though neither was in failure 


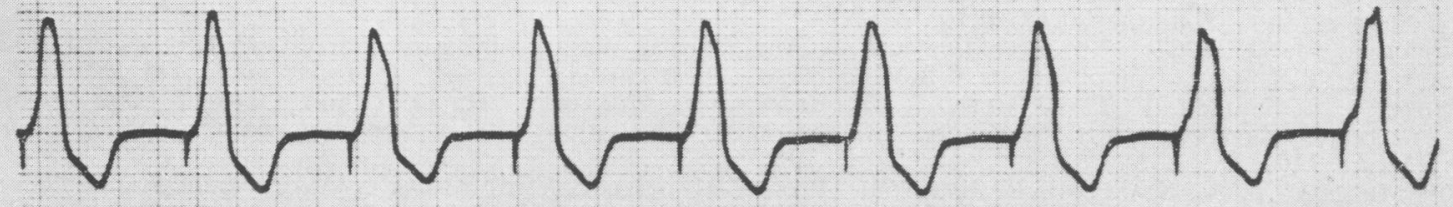

Fig. 8.-Same patient as Figs. 6 and 7 showing control of rhythm by elctrode catheter. The initial negative deflections are the pacemaker artefacts, regularly followed by wide QRS complexes and $T$ waves.

at the time of arrest, the first had a very large heart from longstanding mitral incompetence, and the second widespread antero-septal necrosis with damage to the conducting tissue. Case 7 demonstrates the possibility of maintaining cerebral blood flow by external compression of a heart no longer capable of effective action. When acidosis has been corrected in such a case, and procaine amide and adrenaline tried without effect, nothing is to be gained by prolonging the attempt at resuscitation.

\section{Conclusion}

With the exception of Case 1 , chosen to illustrate the use of thoracotomy and direct defibrillation, the episodes quoted above are drawn from the experience of a teaching hospital cardiac department in the space of a year. Resuscitation was attempted during this period in numerous other patients, though survivals were uncommon. By the nature of things, most instances of cardiac arrest are the consequence of serious disease of the heart itself where the restoration of normal function is impossible, no matter how promptly action is taken. The sort of results to be expected are shown by fairly large series such as that of Klassen and colleagues (Klassen, Broadhurst, Peretz and Johnson, 1963) who reported survival, with discharge from hospital, in 17 out of 117 unselected patients in whom resuscitation was attempted on medical wards. In Jude and colleagues' series (Jude, Kouwenhoven and Knickerbocker, 1961) a quarter of the arrests in 118 patients occurred in or near the operating theatre and of the total 28 survived to leave hospital. Shipman, McCrady and Bradford
(1962) in a smaller series report survival in 10 out of 30 patients; though of 15 with coronary artery disease only one survived. Such accounts are supported by a host of small reports dealing with single cases of successful resuscitation, often in striking circumstances, and with results very gratifying to those concerned. These facts are far from discouraging, and have shown that modern techniques and equipment make it possible to save many patients who 10 years ago would have stood little or no chance of rescue. Discretion will always be required in the application of new methods of treatment, but in principle it is as illogical to withold resuscitatory measures as being "contrary to nature" from, say, a man who collapses after an infarct, as it would be to withold insulin from a diabetic in a coma.

Anyone involved in a series of attempts at resuscitation, whether in the theatre, wards, casualty department, or in less favourable circumstances outside hospital, will inevitably see more failures than successes. Since minutes are precious in this emergency, an element of chance will always be present, determining where the accident occurs and who is present at the time. Thereafter, the management of any case demands optimally the prompt attention of a team of helpers-one to perform massage, one to ventilate the lungs, one to set up an intravenous drip, one to manage the ECG and report changes in rhythm and one to provide drugs as required. Familiarity with the procedure by as large a number of medical and nursing staff as possible is therefore a prerequisite of success.

\section{REFERENCES}

Baringer, J. R., Salzman, E. W. Jones, W. A. Friedlich, A. L. (1961): External cardiac massage. New Engl. J. Med. 265, 62.

BECK, C. S. (1941): Resuscitation for cardiac standstill and ventricular fibrillation occurring during operation. Amer. J. Surg., 54, 273.

BeCK, C. S., WeCKesser, E. C., BARRY, F. M. (1956): Fatal heart attack and successful defibrillation. New concepts in coronary artery disease. J. Amer. med. Ass. 161, 434. 
Bentall, H. B. (1962): External cardiac massage. Proc. roy. Soc. Med. 55, 657.

BERNIER, G. M. (1962): Maintenance of consciousness during closed chest cardiac massage. J. Amer. me Ass. 181, 446.

Brooks, D. K. and Feldman, S. A. (1962): Metabolic acidosis. A new approach to "neostigmine-resistant curarisation". Ancesthesia, 17, 161 .

CHURCHER, M. D. (1962): Noradrenaline and external cardiac massage in cardiac arrest. Brit. med. J. i, 132

Clark, D. T. (1962): Complications following closed chest cardiac massage. J. Amer. med. Ass. 181, 337. ?

COHEN, A. I., SumNer, R. C., Whalen, R. E., Brown, I., MCINTOSH, H. D. (1962): Closed chest cardia massage. Survival after 55 minutes of ventricular fibrillation without apparent sequelæ. Arch. inter Med., 110, 57.

Don Michael, T. A., Stanford, R. L. (1963): Precordial percussion in cardiac asystole. Lancet, i, 699.

DON Michael, T. A., TAYLOR, D. J .E., WARLTHIER, A. W. (1962): The management of cardiac arrest

a general hospital. Postgrad med. J., 38, 560.
EberT, P. A., Greenfield, L. J., AuSteN, W. G., Morrow, A. G. (1962): The relationship of blood pH during profound hypothermia to subsequent myocardial function. Surg. Gynec. Obstet. 114, 357.

Furman, S., SchWEDEL, J. B., Robinson, G., HuRWITT, E. S. (1961): Use of an intracardiac pacemaker in the control of heart block. Surgery, 49, 98.

HaRden, K., Mackenzie, I. L., Ledingham, I. McA. (1963): Spontaneous reversion of ventricular fibrillatio Lancet, ii, 1140.

Herrod, C. E., Lee, R. H., Coggans, W. H. McKombs, R. K., Gerbode, F. (1952): Control of heart actio by repetitive electrical stimuli. Ann. Surg., 136, 510 .

HOOKER, D. R. (1929): On the recovery of the heart in electric shock. Amer. J. Physiol. 91, 305.

HOOKER, D. R. KOUWENHOVEN, W. B., LANGWORTHY, O. R. (1933): The effect of alternating electric currenis on the heart. Amer. J. Physiol., 103, 444.

Hyman, A. S. (1932): Resuscitation of the stopped heart by intracardiac therapy. Experimental use of aim artificial pacemaker. Arch intern. Med., 50, 283. JuDE, J. R., KouWENHOVEN, W. B., KNICKERBOCKER, C. G. (1961): Cardiac arrest. Report of application of
external cardiac massage on 118 patients. J. Amer. med. Ass., 178, 1063.

JuliaN, D. C. (1961): Treatment of cardiac arrest in acute myocardial ischæmia and infarction. Lancet it, 840.

Klassen, G. A., Broadhurst, C., Peretz, D. I., Johnson, A. L. (1963): Cardiac resuscitation in 126 medicat patients using external cardiac massage. Lancet i, 1290.

Kouwenhoven, W. B., Milner, W. R., KNickerbocker, G. G., Chesnut, W. R. (1957): Closed chest defibifi lation of heart. Surgery, 42, 550 .

Kouwenhoven, W. B., JUDE, J. R., KNickerbocker, G. G. (1950): Closed chest cardiac massage. J. A med. Ass., 173, 1064.

LANDGREN, J., BIORKE, G. (1963): The clinical assessment and treatment of complete heart block and Adam Stokes attacks. Medicine, 42, 171.

Leatham, A., CoOK, P., Davies, J. G. (1956): External electric stimulator for treatment of ventricular stan still. Lancet ii, 1185 .

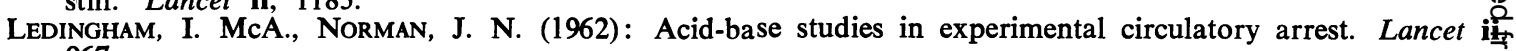
967.

Lown, B., Amarasingham, R., Neuman, J. (1962): New method for terminating cardiac arrhythmias. Usể of a synchronised capacitor discharge. J. Amer. med. Ass., 182, 548 .

ModY, S. M. and RICHINGS, M. (1962): Ventricular fibrillation resulting from electrocution during cardia䟠 catheterisation. Lancet ii, 698.

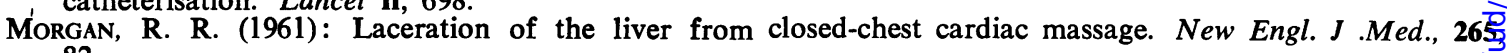
82. Oram, S., Davies, J. P. H., Weinbren, I., TAGgart, P., KITchen, L. D. (1963): Conversion of atrial fibrillaj
tion to sinus rhythm by direct current countershock. Lancet ii, 160.

Portal, R. W., Davies, J. G., Leatham, A., Siddons, A. H. M. (1962): Artificial pacing for heart blocki Lancet, ii, 1369. Safar, P., BRown, T. C., Holtey, W. J. (1962): Failure of closed chest cardiac massage to produce pub
monary ventilation. Dis. Chest, 41, 1. SCHERF, D. and BORNEMANN, C. (1960): Thumping of the precordium in ventricular standstill. Amer.
Cardiol, 5, 30.

Shipman, K. H., MCCrady, W. and Bradford, H. A. (1962): Closed chest cardiac resuscitation. One year results. Amer. J. Cardiol., 10, 551 .

SIDDONS, H. and DAvies, J. G. (1963): A new technique for internal cardiac pacing. Lancet ii, 1204. SIDDONS, H. and SAVIES, J. S. S. (1964): Management of cardiac arrest with special reference to metabolic acidosis. Brif
med. J., i, 476 .

WeAll, F. E. and Rothwell-JACKSON, R. L. (1962): The efficiency of cardiac massage. Lancet, i, 990.

WETHERILL, J. H. and NiXON, P. G. F. (1962): Spontaneous cessation of ventricular fibrillation during externid cardiac massage. Lancet, i, 993.

Wiggers, C. J. (1936): Cardiac massage followed by countershock in revival of mammalian ventricles fror fibrillation due to coronary occlusion. Amer. J. Physiol., 116, 161.

WigGers, C. J. (1940): The physiological basis for cardiac resuscitation from ventricular fibrillation. Metho for serial defibrillation. Amer. Heart J., 20, 413. Zoll, P. M. (1952): Resuscitation of the heart in ventricular standstill by external electric stimulation. Ne
Engl. J. Med., 247, 768 .

Zoll, P. M., Linenthal, A. J., Norman, L. R., Belgard, A. H. (1954): Treatment of Stokes-Adams diseas\& by external electric stimulation of the heart. Circulation 9, 482.

Zoll, P. M., Linenthal, A. J., Gibson, W., PAul, M.H., Norman, L. R. (1956): Termination of ventricular fibrillation in man by externally applied electric countershock. New Engl. J. Med., $254,727$. 